\title{
Oswaldotrema nacinovici gen. nov. sp. nov. (Digenea: Philophthalmidae) from Numenius phaeopus (Aves: Scolopacidae) in Brazil
}

\author{
Luís C Muniz-Pereira ${ }^{+}$, Roberto Magalhães Pinto* \\ Laboratório de Helmintos Parasitos de Vertebrados, Departamento de Helmintologia, Instituto Oswaldo Cruz, \\ Av. Brasil 4365, 21045-900 Rio de Janeiro, RJ, Brasil
}

A new genus, Oswaldotrema gen. nov. is proposed. Oswaldotrema nacinovici sp. nov. is descibed from Numenius phaeopus Latham, 1790. Differentiation from the other related genera, namely Philophthalmus, Pygorchis, Proctobium, Parorchis, Echinostephila, Cloacitrema, Pittacium, Ophthalmotrema, Skrjabinovermis and Paratrema, was based on morphological characters, mainly on those referring to the body surface, body shape, head, esophagus, pharynx, acetabulum, vitellaria, vitelline reservoir and seminal vesicle.

Key words: Digenea - Philophthalmidae - new taxa - Scolopacidae - birds - Brazil

Digeneans parasites of the whimbrel, Numenius phaeopus Latham, 1790, were subject of several studies, many of them summarized by Dronen and Badley (1979). The present paper is the first to refer a helminth parasitizing N. phaeopus in Brazil, despite the efforts of great Brazilian helminthologists that in this century established the Helminthological Collection of the Instituto Oswaldo Cruz (CHIOC), the biggest in South America, based on large field works, reinforcing the importance of collecting vertebrate hosts, in order to increase the amount of data related to biodiversity in our country.

The subfamily Philophthalminae Looss, 1899, allocated by Looss (1899) in the family Fasciolidae Railliet, 1895, was elevated by Travassos (1918) to the rank of family as Philophthalmidae, to accommodate the genera Philophthalmus Looss, 1899, Pygorchis Looss, 1899 and Proctobium Travassos, 1918. Seven genera are presently included to this family, Parorchis Nicoll, 1907; Echinostephilla Lebour, 1909; Cloacitrema Yamaguti, 1935; Pittacium Szidat, 1939 for the species Distomum pittacium Braun, 1901; Ophthalmotrema Sobolev, 1943; Skrjabinovermis Belopolskaya, 1953 and Paratrema Dronen \& Badley, 1979.

\section{MATERIALS AND METHODS}

The two specimens (one male and one female) of Numenius phaeopus Latham, 1790, and the helminth (from the female) were collected and processed for study, respectively, as reported earlier (Muniz-Pereira \& Amato 1995, 1998). Capture of the hosts occurred between October 1989 and October 1990, in the mouth of Piraque river and adjoining mudflat areas (Pedra de Guaratiba), Rio de Janeiro, State of Rio de Janeiro, Brazil. Birds were deposited as type host specimens, sensu Brooks (1993), in the Ornithological Collection of the Museu Nacional do Rio de Janeiro (UFRJ). The ecological term (prevalence) is used according to Bush et al. (1997). Measurements are in micrometers, unless otherwise stated. Photomicrographs were obtained in a Zeiss mod. Axiophot system and the figure was achieved with the aid of a drawing tube connected to an Olympus CBA brightfield microscope. Type specimen was deposited in the CHIOC, Rio de Janeiro, RJ, Brazil. Studied specimens were obtained from CHIOC, Harold W Manter Laboratory of Parasitology (HWML), Museum für Naturkunde Humboldt Universität Berlin, Naturhistorisches Museum Wien and United States National Parasite Collection (USNPC).

\section{RESULTS}

Oswaldotrema gen. nov.

(Figs 1-5)

Diagnosis: body, elliptical. Oral sucker terminal, width less than half of that of acetabulum; head collar absent (Fig. 4); prepharynx short. Esophagus long, without crenulations, bifurcating in front of the genital pore; ceca extending to near poste-

\footnotetext{
${ }^{+}$Corresponding author. Fax: +55-21-260.4866. E-mail: lmuniz@ioc.fiocruz.br

* Research Fellow CNPq (proc. no. 300.374/80-1).

Received 26 August 1999

Accepted 13 January 2000
} 
rior end of body, distally inflated. Acetabulum in middle third of body, nearly equatorial. Testes juxtaposed, lobed, just posterior to germarium, between the two cecal ends. External seminal vesicle tubular, extending dorsally and longitudinally beyond acetabulum (Fig. 2). Cirrus sac small. Germarium nearly median; uterine seminal receptacle conspicuous (Fig. 5). Vitellaria follicular, extending longitudinally from near the end of the external seminal vesicle to testes; vitelline reservoir absent. Uterus intercecal, not intertesticular; metraterm long; eggs containing ocelate miracidia (Figs 1b, 3). Excretory vesicle V shaped.

Etymology: this genus is named after Dr Oswaldo Gonçalves Cruz, in recognition of his contribution to science, in the centenary of the Instituto Oswaldo Cruz.

Type species: Oswaldotrema nacinovici sp. nov.

Oswaldotrema nacinovici sp. nov. (Figs 1-5)

Description: with the characteristics of the genus. Body $3.71 \mathrm{~mm}$ long, greatest width $1.22 \mathrm{~mm}$ at hindbody. Oral sucker 280 long, 260 wide; prepharynx 70 long; pharynx 140 long, 150 wide. Esophagus 530 long, 80 wide; ceca extending up to $91 \%$ of the body length. Acetabulum 670 long, 590 wide. Left testis 410 long, 360 wide, right 290 long, 340 wide, distance between the end of the testes level and posterior extremity of the body 350 long. External seminal vesicle extends 172 posterior to acetabulum. Germarium 137 long, 151 wide; oviducts leaves germarium at posterior end; uterine seminal receptacle filled with sperm, 57 in greatest width. Extension of the vitellaria 950 long, in hindbody. Eggs 61-68 long (median $=65, \mathrm{n}=$ 5), 29 wide.

Etymology: this species is named after Prof. Jorge Bruno Nacinovic, Museu Nacional do Rio de Janeiro, for his works devoted to ornithology.

Taxonomic summary

Type host: Numenius phaeopus Latham, 1790 (female), whimbrel, "maçarico-de-bico-torto"

Site of infection: anterior intestine

Type locality: mouth of Piraque river (Pedra de Guaratiba), Rio de Janeiro, State of Rio de Janeiro, Brazil

Prevalence: $50 \%$

Specimens studied: CHIOC 1288, 11303a-f (Proctobium proctobium, holotype and vouchers), 10697 (Cloacitrema oswaldoi, holotype), 1688216886 (Philophthalmus lachrymosus, vouchers), 33049a-b (Philophthalmus gralli, vouchers). HWML 20863 (Philophthalmus pulchrus, paratype), 30799, 33909,37036, 38223 (Parorchis acanthus, vouchers), 30823 (Cloacitrema

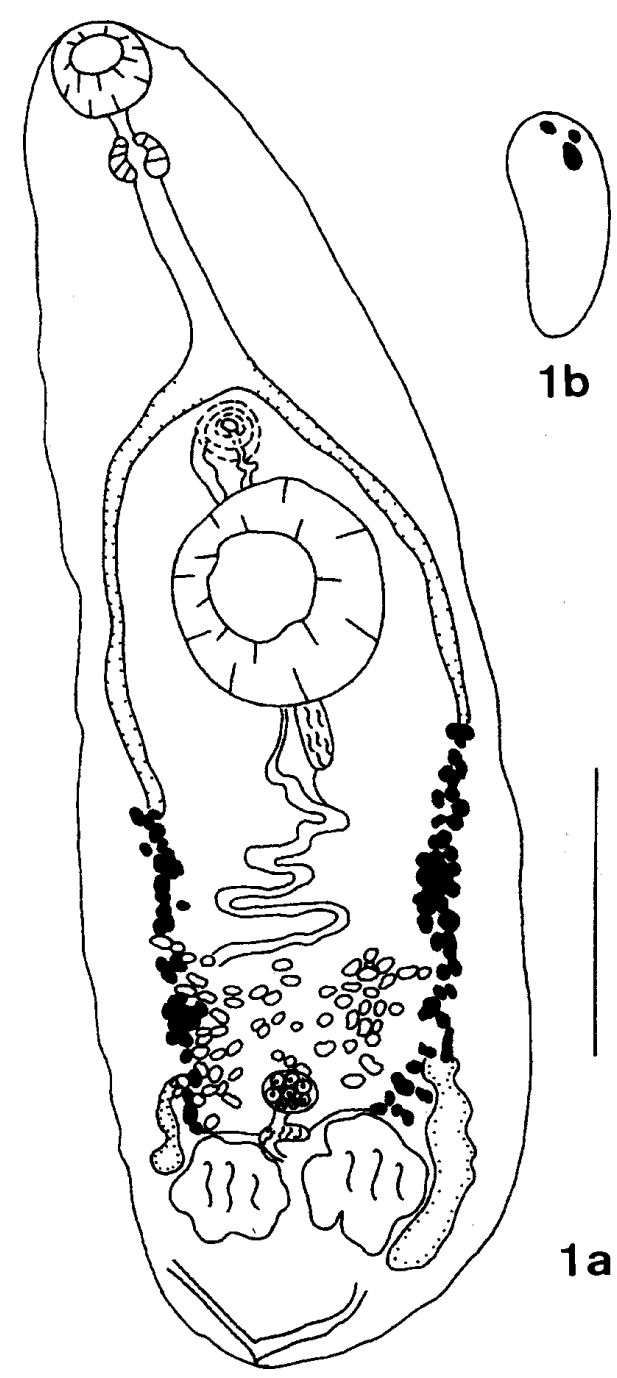

Oswaldotrema nacinovici gen. nov. sp. nov. Fig. 1a: total, ventral view. Fig. 1b: eggs. Bar $=0.08 \mathrm{~mm}$.

michiganensis, voucher), 34849 (Philophthalmus hovorkai, paratype). Museum für Naturkunde Humboldt Universität Berlin 1435, 1436 (Philophthalmus lucipetus, syntypes), 7243 (Philophthalmus hovorkai, syntype). Naturhistorisches Museum Wien 3305-3309, 3311 (Philophthalmus lucipetus, vouchers), 3310 (Philophthalmus hovorkai, voucher), 4661 (Pittacium pittacium, holotype). USNPC 7942, 43491 (Parorchis avitus, vouchers), 9667 (Pygorchis affixus, holotype), 74866, 74867 (Paratrema numenii, holotype and paratype), 75993 (Pygorchis americanus, paratype), 78473, 80794, 81090 (Parorchis acanthus, vouchers). Specimen deposited: holotype - CHIOC 34195 


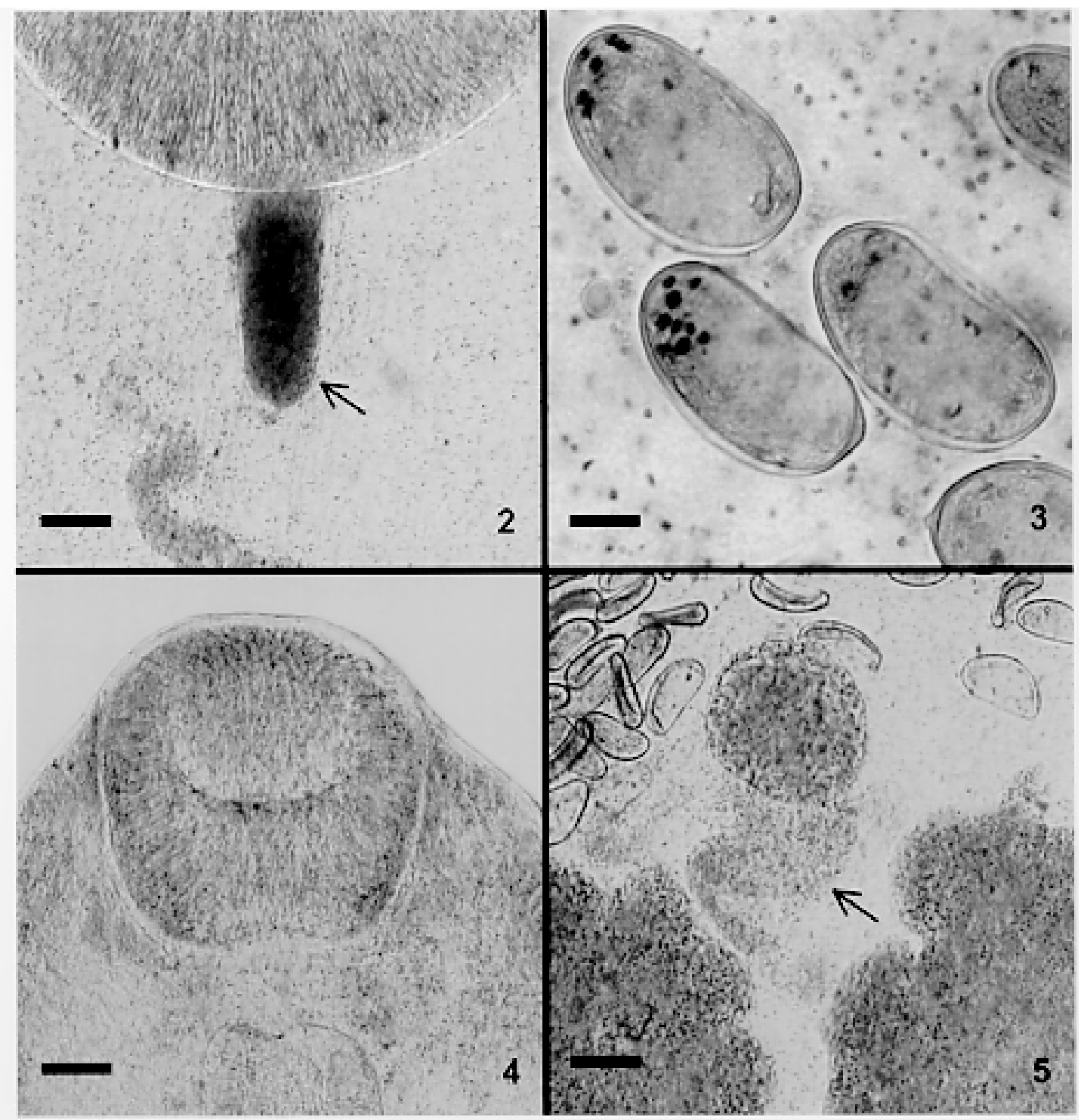

Oswaldotrema nacinovici gen. nov. sp. nov. Fig. 2: acetabular area, external seminal vesicle (arrow), ventral view. Fig. 3: eggs. Fig. 4: anterior extremity, ventral view. Fig. 5: ootype area, uterine seminal receptacle (arrow), ventral view. Figs 2, 4, 5, bar $=0.06 \mathrm{~mm}$. Fig. 3 bar $=0.017 \mathrm{~mm}$.

\section{REMARKS}

The new genus is closely related to Parorchis Nicoll, 1907 and Pygorchis Looss, 1899, but differs from the former in the absence of the head collar and body spines, and from the latter in the longitudinal disposition of the vitellaria and by having a longer esophagus. Also, Pygorchis has a relatively large pharynx when compared to Oswaldotrema gen. nov., that has the diameter of the pharynx almost the half of that of the oral sucker. Philophthalmus Looss, 1899, can be characterized by the absence of the external seminal vesicle, present in the genus described herein.
Proctobium Travassos, 1918, was synonimized with Parorchis by Yamaguti (1971), although Proctobium differs from the latter by the anterior extent of the vitellaria, the absence of crenulations on the esophagus, and the lack of vitelline reservoir. Proctobium can be distinghished from Oswaldotrema gen. nov. by the absence of the head collar.

The most similar genera to the new genus proposed here are Cloacitrema Yamaguti, 1935 and Pittacium Szidat, 1939, that were allocated in the subfamily Cloacitrematinae Yamaguti, 1958 by Yamaguti (1971). Oswaldotrema gen. nov. differs from Cloacitrema by the longer length of the 
esophagus, that is almost absent in Cloacitrema, and by the position of the acetabulum, that is postequatorial in Cloacitrema. In relation to Pittacium, it can be easily distinguished from the new genus, by the shape of the body, that is pearshaped, and not elliptical as Oswaldotrema gen. nov. is. Another differential character is the oral sucker/acetabulum ratio, that in Pittacium is 1:0.27 and in Oswaldotrema gen. nov. is 1:0.42. The distribution of the vitellaria differs in Oswaldotrema gen. nov. and in Pittacium, reaching the acetabular level in the latter and not in the former. In the new genus the testes width is twice the germarium width, whereas in Pittacium these structures present almost the same width.

Lack of data on parasites of $N$. phaeopus in Brazil is probably due to migratory habits of this bird. Considering that the first arrivals in Brazilian wintering grounds occur in September (Hayman et al. 1986), this fact may reduce the opportunity of collecting this host, except for a few non-breeders, that overwinter (Nacinovic 1999 pers. comm.).

According to McNeil et al. (1994, 1995), parasites interfere with migration of their hosts, considering that trematode infection might prevent or delay moulting and fattening in wintering shorebirds. These factors could shed some light in the oversummer and overwinter phenomena, in addition to the hypotheses proposed by previous authors (McNeil 1994). It emphasizes the importance of the studies related to parasites of migratory birds, like Numenius phaeopus, that stay on wintering grounds in Brazil, and possibly are also affected by parasite infections, in relation to the migration to breeding grounds in the northern hemisphere.

\section{ACKNOWLEDGEMENTS}

To Dr Dante M Teixeira, head of the Ornithological Section, Museu Nacional do Rio de Janeiro (UFRJ), for the acceptance of host specimens for deposit; Dr Birger Neuhaus, Curator of the Helminthological Collection of the Museum für Naturkunde Humboldt Universität and Dr Helmutt Sattmann, Curator of the Helminthological
Collection of the Naturhistorisches Museum, for allowing the senior author to examine the specimens in Berlin and Wien, respectively; Dr Ralph Lichtenfels, Curator of the US National Parasite Collection and Dr Scott Gardner, Curator of the Helminthological Collection of the Harold Manter Laboratory, for the loan of the specimens; Geniton José Vieira, from the Instituto Oswaldo Cruz, for technical help in the photomicrograph.

\section{REFERENCES}

Brooks DR 1993. Extending the symbiotype concept to host voucher specimens. J Parasitol 79: 631-633.

Bush AO, Lafferty KD, Lotz JM, Shostak AW 1997. Parasitology meets ecology on its own terms: Margolis et al. revisited. J Parasitol 83: 575-583.

Dronen NO, Badley JE 1979. Helminths of shorebirds from the Texas gulfcoast. I. Digenetic trematodes from the long-billed curlew, Numenius americanus. J Parasitol 65: 645-649.

Hayman P, Marchand J, Prater T 1986. Shorebirds: an Identification Guide to the Waders of the World, Christopher Helm Publishers, London, 412 pp.

Looss A 1899. Weitere beiträge zur kenntnis der trematodenfauna Aegyptens, zugleich versuch einer natürlichen gliederung des genus Distomum retzius. Zool Jahrb Syst 12: 521-784.

McNeil R, Diaz MT, Casanova B, Villeneuve A 1995. Trematode parasitism as a possible factor in oversummering of greater yellowlegs (Tringa melanoleuca). Ornitol Neotrop 6: 57-65.

McNeil R, Diaz MT, Villeneuve A 1994. The mystery of shorebird over-summering: a new hypothesis. Ardea 82: 143-152.

Muniz-Pereira LC, Amato S 1995. Natural hosts of Notocotylus breviserialis (Digenea, Notocotylidae) parasite of Brazilian waterfowl. Mem Inst Oswaldo Cruz, 90: 711-714.

Muniz-Pereira LC, Amato S 1998. Fimbriaria fasciolaris and Cloacotaenia megalops (Eucestoda, Hymenolepididae), cestodes from Brazilian waterfowl. Mem Inst Oswaldo Cruz 93: 767-772.

Travassos L 1918. Novo tipo de Philophthalmidae. Rev Soc Brasil Sc 2: 75-77.

Yamaguti S 1971. Synopsis of Digenetic Trematodes of Vertebrates, Vol. 1, Keigaku Publ. Co., Tokyo, 1074 pp. 